Bangladesh J. Sci. Ind. Res. 42(2), 229-234, 2007

\title{
Influence of Root and Leaf Extracts of Argemone mexicana on Germination and Seedling Growth of Blackgram, Rapeseed and Wheat
}

\author{
N. K. Paul and N. Begum \\ Department of Botany, Rajshahi University, Rajshahi 6205, Bangladesh
}

\begin{abstract}
Allelopathic effect of different concentrations (0, 20, 40 and 60\%) of root and leaf extracts of obnoxious weed Argemone mexicana on germination and seedling growth of blackgram, rapeseed and wheat varieties was studied. Percentage of germination and lengths of main root and shoot and seedling dry weight were highly significantly decreased with the increase of both root and leaf extracts. In some cases, root extract was more inhibitory, but in others leaf extract was more inhibitory. Among the varieties, Dhali of rapeseed and Akbar of wheat were most sensitive to the aqueous extract of Argemone mexicana.
\end{abstract}

\section{Introduction}

The influences of weeds on crops and vice versa have important implications in agriculture, as these govern and direct the planning of suitable agricultural operations. An understanding of the effects of weeds on seed germination and seedling growth of crop plants is essential in exploiting the possible improvement of crop productivity by eliminating the alien weed from the field.

The soluble allelochemicals from weeds which leach out come into direct contact with crop root. There are several reports, which indicate that allelopathic potentiality of weeds plays a major role by affecting the crop growth and nutrient status of soil (Bhowmik and Doll, 1984; Pande et.al., 1980; Pandya, 1975; Qudhia, et.al., 1997; Qudhia, 2000; Kalita, 2001). Pande and his coworkers (Pande et.al., 1980). reported that extracts of root, leaf, stem and unripe fruit of Argemone mexicana were growth regulatory and the root extract was more phytotoxic. Datta and Chakrabarti (Datta and Chakraborti, 1975) observed that leaf extract of Clerodendrum inhibited seed germination and the inhibitory effect increased with concentration. Paria and Mukharjee (Paria and Mukharjee, 1981) found that stem + leaf extracts of Alternanthera contain allelopathic potential which exert deleterious influences on germination and seedling growth of rapeseed and rice. It has been reported that higher inhibitory potential of the root extract of Trianthema on Andropogon sorghum could be due to the fact that inhibitory chemical was probably synthesized in the root and then translocated to the stems and leaves (Pandit et al., 1980). But Kalita and Dey (Kalita and Dey, 1998) found that higher inhibitory 
activity was by shoot extract than root extract of some weeds viz. Ageratum cenyzoides, Borreria hispida, Cynodon dactylon and Cyperus rotandus on growth of rice.

Argemone mexicana is a notorious weed and is found abundantly along with many crops. The present investigation was planned to study the effect of root and leaf extracts of Argemone mexicana on germination and seedling growth of three crops.

\section{Materials and Methods}

The materials of the experiment were 4 varieties (Barimash-1, Barimash-2, Barimash-3 and Binamash-1) of blackgram (Vigna mungo L.), 3 varieties (Dhali, Tori 7 and SS 75) of rapeseed (Brassica campestris L.) and 4 varieties (Sourav, Gourab, Akbar and Kanchan) of wheat (Triticum aestivum L.).

Four concentrations (0, 20, 40 and $60 \%)$ of root and leaf extracts of Argemone mexicana were used. Argemone plants were collected from Rajshahi University campus and the root and leaf extracts were prepared separately. The extracts were prepared by cutting Argemone plant parts into small pieces. For preparing $20 \%$ extract, 20 g of each of root and leaf were soaked in $100 \mathrm{ml}$ distilled water separately for 24 hours at room temperature $\left(19-24^{\circ} \mathrm{C}\right)$. In the same way 40 and $60 \%$ extracts were prepared. In case of $0 \%$ treatment, only distilled water was used. The laboratory bioassay was done in $10 \mathrm{~cm}$ diameter petri dishes with one layer of filter paper. Ten seeds of each variety were placed in each petri dish. After keeping the seeds into petri dish, $10 \mathrm{ml}$ of distilled water was added to the control treatment and $10 \mathrm{ml}$ aqueous extract were applied at concentrations mentioned above. The petri dishes were arranged in a randomized block design with 3 replications. On alternate days, $10 \mathrm{ml}$ of distilled water was added to the control and $10 \mathrm{ml}$ of aqueous extract was added to the treatment petri dishes according to the gradient.

Number of seeds germinated on each day was counted. At the tenth day, the main root length and shoot length were measured. For obtaining seedling dry weight, seedlings were kept in an oven at $60^{\circ} \mathrm{C}$ for 48 hours. Statistical analysis was performed accordingly for all the characters by a statistical package named Irristat Version 3.1 to show the significant difference.

\section{Results and Discussion}

In case of root extract of Argemone, varietal differences were significant $(p=0.01)$ for all the four characters of blackgram, rapeseed and wheat except seedling dry weight of rapeseed. Treatment differences were significant $(p=0.01)$ for all the characters of all the three crops. Variety $\mathrm{x}$ treatment interactions were significant $(p=0.05)$ for all the characters of blackgram and rapeseed and in wheat only shoot length and seedling dry weight.

In case of leaf extract, varietal differences were significant $(p=0.05)$ for all the characters except main root length of blackgram, all the characters except main root length of rapeseed and all the characters of wheat. Treatment effect was significant $(p=0.01)$ for all the characters of three crops. Variety and treatment interactions were significant $(p=0.05)$ for all the characters except 
seedling dry weight of rapeseed, only seedling dry weight of blackgram and in case of wheat all the characters except shoot length and seedling dry weight.
Mean effects of Argemone on \% of germination and seedling growth are presented in Tables I, II and III respectively for blackgram, rapeseed and wheat. In blackgram, both the root and leaf extracts of Argemone

Table I. Mean values of germination $\%$ and seedling growth characters of blackgram as affected by root and leaf extracts of Argemone

\begin{tabular}{|c|c|c|c|c|c|c|c|c|c|c|}
\hline Treatment & $0 \%$ & $20 \%$ & $40 \%$ & $60 \%$ & Mean & $0 \%$ & $20 \%$ & $40 \%$ & $60 \%$ & Mean \\
\hline Variety & \multicolumn{5}{|c|}{$\%$ of germination (angular values) } & \multicolumn{5}{|c|}{ Main root length $(\mathrm{mm})$} \\
\hline \multirow[t]{2}{*}{ Barimash 1} & $80^{* *}$ & 63 & 63 & 54 & 66 & 53 & 51 & 36 & 33 & 43 \\
\hline & 80 & 63 & 62 & 55 & 65 & 53 & 17 & 15 & 8 & 23 \\
\hline \multirow[t]{2}{*}{ Barimash 2} & 90 & 84 & 84 & 72 & 83 & 61 & 53 & 23 & 19 & 38 \\
\hline & 90 & 84 & 82 & 74 & 83 & 61 & 16 & 13 & 7 & 24 \\
\hline \multirow[t]{2}{*}{ Barimash 1} & 90 & 71 & 61 & 60 & 71 & 46 & 25 & 20 & 17 & 27 \\
\hline & 90 & 70 & 62 & 61 & 71 & 46 & 28 & 16 & 13 & 26 \\
\hline \multirow[t]{2}{*}{ Barimash 3} & 72 & 67 & 60 & 57 & 64 & 79 & 58 & 55 & 51 & 61 \\
\hline & 72 & 67 & 60 & 57 & 64 & 79 & 60 & 41 & 40 & 55 \\
\hline \multirow[t]{2}{*}{ Mean } & 83 & 72 & 67 & 61 & & 60 & 47 & 33 & 30 & \\
\hline & 83 & 80 & 75 & 67 & & 60 & 30 & 21 & 17 & \\
\hline \multirow[t]{2}{*}{ LSD $5 \%$} & (1) 6 & (2) 6 & & & & (1) 6 & (2) 6 & & & \\
\hline & (1) 5 & (2) 5 & & & & (1) 7 & (2) 7 & & & \\
\hline Treatment & $0 \%$ & $20 \%$ & $40 \%$ & $60 \%$ & Mean & $0 \%$ & $20 \%$ & $40 \%$ & $60 \%$ & Mean \\
\hline Variety & \multicolumn{5}{|c|}{ Seedling length (mm) } & \multicolumn{5}{|c|}{ Dry weight/ seeding (mg) } \\
\hline \multirow[t]{2}{*}{ Barimash 1} & 193 & 178 & 174 & 155 & 175 & 193 & 178 & 174 & 155 & 175 \\
\hline & 193 & 192 & 187 & 165 & 184 & 193 & 192 & 187 & 165 & 184 \\
\hline \multirow[t]{2}{*}{ Barimash 2} & 209 & 184 & 150 & 131 & 169 & 209 & 184 & 150 & 131 & 169 \\
\hline & 209 & 189 & 184 & 177 & 190 & 209 & 189 & 184 & 177 & 190 \\
\hline \multirow[t]{2}{*}{ Barimash 1} & 219 & 185 & 171 & 139 & 178 & 219 & 185 & 171 & 139 & 178 \\
\hline & 219 & 202 & 175 & 174 & 193 & 219 & 202 & 175 & 174 & 193 \\
\hline \multirow[t]{2}{*}{ Barimash 3} & 215 & 185 & 173 & 152 & 181 & 215 & 185 & 173 & 152 & 181 \\
\hline & 215 & 196 & 171 & 163 & 186 & 215 & 196 & 171 & 163 & 186 \\
\hline \multirow[t]{2}{*}{ Mean } & 209 & 184 & 167 & 144 & & 209 & 184 & 167 & 144 & \\
\hline & 209 & 195 & 179 & 170 & & 209 & 195 & 179 & 170 & \\
\hline \multirow[t]{2}{*}{ LSD $5 \%$} & (1) 8 & (2) 8 & & & & (1) 8 & (2) 8 & & & \\
\hline & (1) 10 & (2) 10 & & & & (1) 10 & (2) 10 & & & \\
\hline
\end{tabular}

*In each pair upper value and lower values indicate effect of root and leaf extract, respectively for all tables. LSD $5 \%$ (1) for variety and (2) for treatment 
inhibited \% of germination, root length and seeding dry weight of all the four varieties.

However, root extracts was more effective on shoot length and seeding dry weight, but leaf extract was more effective on root length. The inhibition was increased with the increase of concentration of the extracts (Table I).
In rapeseed, both the root and leaf extracts inhibited all the characters studied and the inhibition increased with the increase of concentration. However, leaf extract was more effective than root extract for all the characters. Seed germination in Dhali was completely checked in $60 \%$ leaf extract. Seed of Tori 7 and SS 75 germinated, but their plumule and radicle did not develop. In

Table II. Mean values of germination \% and seedling growth characters of rapeseed as affected by root and leaf extracts of Argemone

\begin{tabular}{|c|c|c|c|c|c|c|c|c|c|c|}
\hline Treatment & $0 \%$ & $20 \%$ & $40 \%$ & $60 \%$ & Mean & $0 \%$ & $20 \%$ & $40 \%$ & $60 \%$ & Mean \\
\hline Variety & \multicolumn{5}{|c|}{ \% of germination (angular values) } & \multicolumn{5}{|c|}{ Main root length (mm) } \\
\hline \multirow[t]{2}{*}{ Dhali } & 80 & 80 & 64 & 42 & 66 & 94 & 32 & 29 & 23 & 44 \\
\hline & 80 & 80 & 45 & - & 51 & 94 & 17 & - & - & 28 \\
\hline \multirow[t]{2}{*}{ Tori 7} & 90 & 90 & 67 & 60 & 77 & 65 & 25 & 22 & 13 & 32 \\
\hline & 90 & 90 & 60 & 15 & 64 & 65 & 25 & 9 & - & 25 \\
\hline \multirow[t]{2}{*}{ SS 75} & 90 & 54 & 60 & 57 & 72 & 61 & 41 & 37 & 33 & 43 \\
\hline & 90 & 80 & 54 & 18 & 54 & 61 & 31 & 11 & - & 26 \\
\hline \multirow[t]{2}{*}{ Mean } & 87 & 83 & 64 & 53 & & 73 & 33 & 29 & 23 & \\
\hline & 87 & 74 & 63 & 11 & & 73 & 24 & 7 & - & \\
\hline \multirow[t]{2}{*}{ LSD $5 \%$} & (1) 5 & (2) 8 & & & & (1) 7 & (2) 9 & & & \\
\hline & (1) 4.8 & (2) 5.5 & & & & (1) 7 & (2) 9 & & & \\
\hline Treatment & $0 \%$ & $20 \%$ & $40 \%$ & $60 \%$ & Mean & $0 \%$ & $20 \%$ & $40 \%$ & $60 \%$ & Mean \\
\hline Variety & \multicolumn{5}{|c|}{ Seedling length (mm) } & \multicolumn{5}{|c|}{ Dry weight/ seeding (mg) } \\
\hline \multirow[t]{2}{*}{ Dhali } & 46 & 44 & 44 & 25 & 40 & 21 & 20 & 7 & 6 & 13 \\
\hline & 46 & 28 & - & - & 19 & 21 & 12 & - & - & 8 \\
\hline \multirow[t]{2}{*}{ Tori 7} & 56 & 55 & 44 & 29 & 46 & 22 & 20 & 12 & 10 & 16 \\
\hline & 56 & 40 & 35 & - & 33 & 22 & 15 & 5 & - & 10 \\
\hline \multirow[t]{2}{*}{ SS 75} & 46 & 45 & 30 & 28 & 37 & 20 & 19 & 6 & 6 & 13 \\
\hline & 46 & 17 & 17 & - & 20 & 20 & 13 & 4 & - & 9 \\
\hline \multirow[t]{2}{*}{ Mean } & 49 & 48 & 39 & 27 & & 21 & 19 & 8 & 7 & \\
\hline & 49 & 28 & 17 & - & & 21 & 13 & 2 & - & \\
\hline \multirow[t]{2}{*}{ LSD 5\% } & (1) 4 & (2) 2 & & & & (1) NS & (2) 3 & & & \\
\hline & (1) 3 & (2) 4 & & & & (1) 2 & (2) 2 & & & \\
\hline
\end{tabular}

*In each pair upper value and lower values indicate effect of root and leaf extract, respectively for all tables. LSD 5 \% (1) for variety and (2) for treatment 
$40 \%$ leaf extract, seeds of Dhali germinated, but plumule and radicle were destroyed at last (Table II).

In case of wheat, all the characters of all the varieties were inhibited by root and leaf extracts. However, root extract was more effective on germination percentage and seedling dry weight and leaf extract on main root length and shoot length (Table III). It is interesting to note that Gourab maintained higher $\%$ of germination in higher concentra-

Table III. Mean values of germination $\%$ and seedling growth characters of wheat as affected by root and leaf extracts of Argemone

\begin{tabular}{|c|c|c|c|c|c|c|c|c|c|c|}
\hline Treatment & $0 \%$ & $20 \%$ & $40 \%$ & $60 \%$ & Mean & $0 \%$ & $20 \%$ & $40 \%$ & $60 \%$ & Mean \\
\hline Variety & \multicolumn{5}{|c|}{$\%$ of germination (angular values) } & \multicolumn{5}{|c|}{ Main root length (mm) } \\
\hline \multirow[t]{2}{*}{ Sourav } & 77 & 55 & 55 & 40 & 57 & 142 & 105 & 87 & 70 & 101 \\
\hline & 77 & 76 & 60 & 55 & 67 & 142 & 72 & 60 & 22 & 74 \\
\hline \multirow[t]{2}{*}{ Gourab } & 90 & 90 & 90 & 76 & 87 & 186 & 135 & 130 & 105 & 139 \\
\hline & 90 & 90 & 90 & 60 & 83 & 186 & 73 & 71 & 18 & 87 \\
\hline \multirow[t]{2}{*}{ Akbar } & 55 & 55 & 45 & 35 & 48 & 127 & 117 & 107 & 90 & 110 \\
\hline & 55 & 55 & 55 & 50 & 54 & 127 & 70 & 69 & 17 & 71 \\
\hline \multirow[t]{2}{*}{ Kanchan } & 76 & 60 & 55 & 55 & 62 & 160 & 117 & 114 & 90 & 120 \\
\hline & 76 & 60 & 60 & 55 & 63 & 160 & 71 & 74 & 16 & 81 \\
\hline \multirow[t]{2}{*}{ Mean } & 75 & 65 & 61 & 52 & & 154 & 118 & 109 & 88 & \\
\hline & 75 & 70 & 66 & 55 & & 154 & 72 & 69 & 18 & \\
\hline \multirow[t]{2}{*}{ LSD 5\% } & (1) 8 & (2) 8 & & & & (1) 13 & (2) 13 & & & \\
\hline & (1) 5 & (2) 5 & & & & (1) 11 & (2) 11 & & & \\
\hline Treatment & $0 \%$ & $20 \%$ & $40 \%$ & $60 \%$ & Mean & $0 \%$ & $20 \%$ & $40 \%$ & $60 \%$ & Mean \\
\hline Variety & \multicolumn{5}{|c|}{ Seedling length (mm) } & \multicolumn{5}{|c|}{ Dry weight/ seeding (mg) } \\
\hline \multirow{2}{*}{ Sourav } & 159 & 153 & 138 & 146 & 149 & 98 & 53 & 23 & 21 & 49 \\
\hline & 159 & 157 & 137 & 115 & 142 & 98 & 87 & 81 & 72 & 84 \\
\hline \multirow[t]{2}{*}{ Gourab } & 167 & 152 & 148 & 104 & 158 & 134 & 124 & 122 & 115 & 124 \\
\hline & 167 & 156 & 153 & 115 & 147 & 134 & 121 & 128 & 97 & 132 \\
\hline \multirow[t]{2}{*}{ Akbar } & 184 & 179 & 173 & 158 & 173 & 103 & 70 & 54 & 44 & 68 \\
\hline & 184 & 182 & 178 & 148 & 173 & 103 & 100 & 96 & 63 & 90 \\
\hline \multirow[t]{2}{*}{ Kanchan } & 139 & 136 & 123 & 121 & 130 & 124 & 100 & 74 & 73 & 93 \\
\hline & 139 & 145 & 125 & 108 & 129 & 124 & 117 & 92 & 86 & 106 \\
\hline \multirow[t]{2}{*}{ Mean } & 162 & 155 & 146 & 147 & 152 & 115 & 87 & 68 & 63 & 83 \\
\hline & 162 & 160 & 148 & 121 & 148 & 115 & 108 & 99 & 79 & 100 \\
\hline \multirow{2}{*}{ LSD 5 \% } & (1) 6 & (2) 6 & & & & (1) 14 & (2) 14 & & & \\
\hline & (1) 7 & (2) 7 & & & & (1) 7 & (2) 7 & & & \\
\hline
\end{tabular}

*In each pair upper value and lower values indicate effect of root and leaf extract, respectively for all tables. LSD 5 \% (1) for variety and (2) for treatment. 
tions of both root and leaf extracts. This indicates that Gourab is the most tolerant variety. Akbar was the most sensitive for germination among the varieties (Table III). Similar to the present results, a number of workers have reported inhibitory effects of extract of weeds on crop plants (Pande et.al., 1980; Pandya, 1975; Qudhia, et.al., 1997; Kalita, 2001).

The results of the present investigation indicate that some phytotoxic substances are synthesized and stored in the root and leaf of Argemone. No attempt was made to isolate these substances. Further, whether these phytotoxic substances are excluded into the soil in the natural conditions is still to be determined, although in the case of weeds like Artemisia absinthium and Encelia farinosa, these phytotoxic substances are effective in natural field conditions (Funke, 1943). The decay of these roots would greatly inhibit the growth of seedlings (Whittaker, 1970). It is, therefore, suggested that Argemone mexicana should be removed along with the roots.

\section{References}

Bhowmik, P.C. and Doll, J.D. (1984) Allelopathic effect of annual weed residues on growth and nutrient uptake of corn and soybean. Agron. J. 76 : 383-388.

Datta, S.C. and Chakraborti, S.D. (1975) Germination and growth inhibitors from Clerodendrum viscosum Vent. Geobios 2 : 188-189.

Funke, G. (1943) The influence of Artemisia absinthium on neighbouring plants. Blumea 5 : 211-293.

Kalita, D. (2001) Allelopathic effect of weeds on physico-chemical properties of rice and nutrient status of soil. Ecol. Env. \& Cons. 7 : 79-85.

Kalita, D. and Dey, S.C. (1998) Allelopathic effect of shoot and root extracts of some weeds on growth of rice. Geobios 25 : 269-272.

Pande, P.C. Dublish, P.K. and Jain, D.K. (1980) Effects of extractys of Argemone mexicana Linn. on seed germination and seedling growth of Abelmoschus esculentus Ser. Bangladesh J. Bot. 9 : 67-71.

Pandit, B.R. Patel, B.P. and Vora, U.A. (1980) Allelopathic potential of Trianthema portulacastrum on Andropogon sorghum (Joar) Sci. \& Cult. 47 : 290-291.

Pandya, S. M. (1975) Effect of Celosia argentea extracts on root and shoot growth of bajra seedlings. Geobios 2 : 175-178.

Paria, N. and Mukharjee, A. (1981) Allelopathic potential of a weed, Alternanthera philoxeroides (Mart) Griseb. Bangladesh J. Bot. 10 : 86-89.

Qudhia, P. (2000) Allelopathic effects of some obnoxious weeds on germination of soybean. Indian J. Plant Physiol. 5 : 295-296.

Qudhia, P. Kolhe, S.S. and Tripathi R.S (1997) Allelopathic effect of Parthenium hysterophorus on germination of linseed. Indian J. Plant Physiol 2 : 327-329.

Whittaker, R.H. (1970) In: Chemical Ecology. (Eds) Sondheimer, E. and Simeon, J.B. pp. 43-66.

Received : August 28, 2006;

Accepted : March 01, 2007 